\title{
Trabalho docente na era digital e saúde de professores universitários ${ }^{1}$
}

\section{Teaching career in the digital age and health of the teachers college}

\section{Trabajo docente en la era digital y salud de profesores universitarios}

\author{
Sálua Cecílio' \\ Briana Manzan Reis" \\ 'Universidade de Uberaba, Minas Gerais - Brasil. E-mail: saluacecilio@netsite.com.br \\ "Universidade de Uberaba, Minas Gerais - Brasil. E-mail: brianamanzan@yahoo.com.br
}

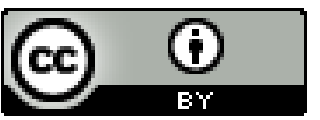

Educação: teoria e prática, Rio Claro, SP, Brasil - eISSN: 1981-8106

Está licenciada sob Licença Creative Common

\section{Resumo}

Neste artigo discutem-se usos das tecnologias digitais no trabalho docente e os desafios daí decorrentes para a atuação e a saúde de professores. O objetivo é analisar a compreensão que eles têm sobre as tecnologias e como entendem seu lugar no ensino superior. A pesquisa baseou-se em entrevistas semiestruturadas com professores do ensino presencial e a distância de uma universidade particular de Minas Gerais. Constata-se que as tecnologias são utilizadas como recursos para exposição do conteúdo de aulas e apoio ao professor na elaboração de atividades docentes. Alguns percebem-nas como concorrentes e outros como aliadas. Cada vez mais presentes no cotidiano dos docentes, podem levar a uma intensificação do trabalho. As tarefas mostram-se mais diversificadas e complexas. Requerem permanente dedicação, empenho e tempo de trabalhos constantes e prolongados. Assim, o tempo dedicado à profissão torna-se maior do que o esperado e viável para os professores, ocasionando jornadas de trabalho exaustivas e redução da saúde.

Palavras-chave: Docência e tecnologia. Professores. Educação à distância. Trabalho docente. Saúde.

\footnotetext{
${ }^{1}$ Título abreviado: Trabalho docente e saúde
} 


\begin{abstract}
This paper discusses the use of digital technologies in teaching and the resulting challenges for the performance and health of teachers. The aim is to analyze the understanding they have of the technologies and how to understand their place in higher education. The research based on semi-structured interviews with teachers who teach face-to-face and online classes from of a private University of Minas Gerais state. It appears that the technologies are used as resources to display content classes and teacher support in the development of teaching activities. Some perceive them as competitors and other as allies. Increasingly present in the daily lives of teachers, can lead to an intensification of work. The tasks are shown to be more diverse and complex in this case. They require permanent dedication, commitment and time constant and prolonged work. Thus, the time dedicated to the profession becomes larger than expected and feasible for teachers, causing extensive working hours and reducing health.
\end{abstract}

Keywords: Teaching and technology. Teachers. Distance education. Teaching. Health.

\title{
Resumen
}

En este artículo se discuten los usos de las tecnologías digitales en el trabajo docente y los desafios derivados de estos para la actuación y la salud de los profesores. El objetivo es analizar la comprensión que ellos tienen sobre las tecnologías y cómo entienden su lugar en la enseñanza superior. La investigación se basó en entrevistas semiestructuradas con profesores de la enseñanza presencial y a distancia de una universidad particular de Minas. Se constata que las tecnologías son utilizadas como recursos para exposición del contenido de clases y apoyo al profesor en la elaboración de actividades docentes. Algunos las perciben como competidoras y otros como aliadas. Cada vez más presentes en el cotidiano de los docentes, pueden llevar a una intensificación del trabajo. Las tareas se muestran más diversificadas y complejas. Requieren permanente dedicación, empeño y tiempo de trabajos constantes y prolongados. De este modo, el tiempo dedicado a la profesión se hace mayor que el esperado y viable para los profesores, ocasionando jornadas de trabajo exhaustivas y reducción de la salud.

Palabras clave: Docencia y tecnología. Profesores. Educación a distancia. Trabajo docente. Salud.

\section{Introdução}

Uma invasão tecnológica atinge a sociedade, em seus vários segmentos e instituições, e impõe aos indivíduos crescentes mudanças de hábitos de vida e de trabalho. Nesta direção, aqui se enfoca o trabalho docente em suas relações com tecnologias digitais (TD), com o 
objetivo de mostrar a realidade em mutação contínua, acelerada e sem limites, que altera condições a que os docentes estão expostos e precisam enfrentar a todo instante.

A entrada das TD nos mundos do trabalho e da educação apresenta efeitos objetivos na já reconhecida "verdadeira revolução tecnológica sobre a educação" representada "no aumento da oferta de cursos online no Brasil, ao mesmo tempo em que se observa um aumento significativo no número de pesquisadores dedicados ao tema" (COELHO; HAGUENAUER, 2004, p.2). Há infinitas possibilidades de utilização das tecnologias e é crescente o interesse por elas na educação. Seja para conhecer suas possibilidades, seja para adotá-las, entender seus limites e conscientizar-se de suas implicações para os sujeitos.

Com a expansão tecnológica cada vez maior na educação, o quadro merece reflexões pelo que provoca nos sujeitos e no mundo do trabalho. A ótica não está no aumento da produtividade, mas nas modulações que isso traz para a subjetividade de quem trabalha. Portanto, na interface objetividade e subjetividade no trabalho.

Mesmo percebidas e tidas como recursos de presença generalizada nas atividades docentes, interessa discutir a ausência de unanimidade em relação ao uso e efeitos das TD. Em alguns casos e em algumas áreas, tal modalidade reina soberana, mas não há consenso sobre seus reais benefícios em termos de qualidade e eficiência, extensão, nem do alcance de seu papel, numa sociedade comprometida com a autonomia e o desenvolvimento dos sujeitos e não só com a sua produtividade e desempenho. É isso o que se analisa a seguir.

\section{Metodologia}

Para conhecer como as tecnologias são percebidas e utilizadas no trabalho docente e analisar o que daí resulta para a saúde, realizou-se pesquisa de abordagem qualitativa com professores de uma instituição de ensino superior privado, situada no Triângulo Mineiro, MG. A universidade tem recursos técnico-administrativos habilitados e infraestrutura própria. Conta com salas de aula e ambiente adequados às modalidades de ensino, biblioteca, recursos audiovisuais, núcleo de tecnologia da informação e laboratórios, que favorecem o ensino, a extensão e a pesquisa, em sintonia com o preconizado pelo Projeto Pedagógico Institucional (PPI), que prevê uma formação humanista e ética, articulada às demandas sociais.

A escolha da abordagem se deu em função dos objetivos relacionados à compreensão de singularidades do objeto, sem interesse por resultados que possam ser generalizados. Daí, se considerar que a "[...] amostra qualitativa ideal é a que reflete a totalidade das múltiplas dimensões do objeto de estudo" (MINAYO, 2014, p.197).

A identificação dos sujeitos foi feita pelo site institucional, que disponibiliza o quadro docente dos cursos da universidade. Dada a natureza da pesquisa, e a partir dos critérios de acessibilidade e disponibilidade, foram escolhidos dez professores que se enquadravam nos seguintes quesitos estabelecidos: atuarem nos cursos selecionados considerados em expansão 
na universidade e não terem participado de etapas anteriores do estudo. Dos dez, nove aceitaram participar, sendo quatro do curso de pedagogia, um de administração e quatro de engenharia. Desses professores, dois só atuam na modalidade EaD; quatro na presencial e na EaD; e três na presencial.

Em 2013, a universidade contava com 129 docentes e 5432 alunos nos cursos das engenharias, sendo 3689 nos presenciais e 1743 em EaD; 26 docentes no curso de administração presencial com 530 alunos; 20 docentes na pedagogia, modalidade presencial, com 111 alunos e 9 na modalidade EaD local, com 1162 alunos.

Realizou-se contato com a secretaria de cada curso, para conhecimento dos horários dos professores. Uma vez localizados, os docentes foram esclarecidos sobre o caráter, as condições, a forma de participação na pesquisa e os seus benefícios. Na entrevista, foi entregue ao docente participante o Termo de Consentimento Livre e Esclarecido (TCLE), para conhecimento e assinatura.

Os que aceitaram participar do estudo combinaram com o pesquisador local e horário da entrevista. Foi utilizada a entrevista semiestruturada em torno de questões relativas ao trabalho docente e uso das Tecnologias de Informação e Comunicação (TIC), denominação inicial e mais popularizada que as atualmente hoje chamadas TD.

Previamente agendadas, as entrevistas foram realizadas na universidade e gravadas, para viabilizar as posteriores análises previstas e a fidelidade ao que foi dito. A duração média das entrevistas variou de 23 a 63 minutos. Foram utilizados nomes fictícios para preservar o sigilo das informações e a identidade dos participantes.

Antes e paralelamente à pesquisa de campo, a pesquisa e a seleção dos materiais bibliográficos se deram em sites de banco de dados online como Scientific Electronic Library Online (SCIELO), Google Acadêmico, anais disponíveis no site da Associação Nacional de Pesquisa e Pós-graduação em Educação (ANPED) e livros, conforme definição prévia dos critérios de data de publicação, fixada entre 2002 a 2013, idioma português e assunto pertinente ao tratado no estudo. Foram encontrados 26 artigos, sete livros e um trabalho apresentado e exposto no site da ANPED. Dez artigos, sete livros e o trabalho localizado no site da ANPED, foram selecionados como material de estudo para elaboração da parte teórica, atendendo aos objetivos de delimitação do quadro teórico de referência. Os termos descritores utilizados, para a busca do material, foram: professor e tecnologia; trabalho docente e tecnologia; educação a distância; tecnologia de informação e comunicação; educação e tecnologia.

Os resultados foram organizados a partir das seguintes categorias de análise: avanços tecnológicos; educação a distância; contribuição das tecnologias dentro de sala de aula; dificuldade em lidar com os equipamentos digitais; preferência pelos instrumentos tradicionais de ensino; resistência as tecnologias; tecnologias e o ambiente de estudo e a invasão da vida pessoal desses trabalhadores pelas TD. A análise incluiu os avanços das 
tecnologias, passou pela sua entrada no ambiente educacional e culminou com suas influências e efeitos na relação educação, trabalho e vida dos professores.

\section{Resultados e discussão}

\subsection{Tecnologias digitais e educação}

As TD e sua influência e lugar na educação têm sido amplamente discutidas, as análises são controversas e as conclusões mostram-se diversas.

O uso das tecnologias no espaço escolar, segundo Ens (2002), deu-se através de etapas e progressos que inicialmente incluíram alguns e depois outros. Primeiro quem tinha acesso aos equipamentos de informática eram somente profissionais que trabalhavam nos setores administrativos. Logo em seguida, os professores começaram a ter contato com eles e agora os utilizam para facilitar seu trabalho e elaborar atividades pedagógicas, como provas e trabalhos. Em outro momento, os alunos também demonstraram interesse pelas tecnologias e as escolas viram a necessidade de criar um ambiente próprio (laboratório de informática), para que nele pudessem se familiarizar com as mesmas e aprender a manuseá-las. Com isso, os alunos apresentaram maior interesse pelas aulas nos laboratórios do que em salas tradicionais. O recurso que a escola inicialmente adotou foi a utilização de softwares educativos, para conciliar motivação e aprendizagem e ter um método de ensino satisfatório.

A utilização do computador como "recurso didático-pedagógico contribuiu para a melhora da qualidade do ensino e de aprendizagem e, contudo, o professor é visto como mediador entre o aluno, o computador e o saber" (PEIXOTO; ARAÚJO, 2012, p. 257). No ensino a distância, o professor e o aluno assumem outro papel. Para alguns teóricos e profissionais, o professor é um mediador e o aluno é quem constrói seu conhecimento. Mas, em torno dessa concepção do significado de ser professor não há consenso e unanimidade. Há quem veja no professor um profissional para o qual os papeis clássicos relativos ao ensino permanecem e não podem ser diluídos ou reduzidos à atuação como mediador.

Quanto às repercussões das tecnologias, Coelho e Haguenauer (2004) reconhecem que elas trouxeram grandes avanços para a educação. Entendem que, com o advento da internet, aumentaram muito o campo e as fontes de investigação de pesquisa, até então restritas aos livros, revistas e jornais. Por meio das mídias digitais, é possível realizar atividades, independentemente de onde se estiver. Isso insinua novas condições de trabalho e apresenta desafios ao desenvolvimento pessoal e profissional de quem trabalha.

As tecnologias estão se transformando progressivamente de meio a um fim em si mesmas e exigem que os indivíduos e a sociedade se adaptem a elas; e tal adaptação se processa de maneira violenta, gerando consequências desumanas para seus usuários (PUCCI; CERASOLI, 2010, p. 172-173). 
As exigências do mundo do trabalho requerem cada vez mais profissionais aptos para lidar com as TD, em suas variadas formas de acesso e de recursos. Demandam uma postura e um exercício permanente de abertura ao que é novo e ao que muda, de forma que os docentes se habilitem a entender a realidade e nela agir com a profissionalidade desejável e necessária. Isso para planejar e tornar seu trabalho mais interessante para os alunos, conseguir a atenção dos mesmos, motivá-los e envolvê-los no processo ensino-aprendizagem.

Na área acadêmica, a penetração e o uso de tecnologias vêm crescendo e conseguindo espaço a cada dia. Professores e alunos utilizam-se desses recursos para facilitar a comunicação entre colegas de profissão, favorecer estudos e tornar o ensino e a aprendizagem mais dinâmicos, ilustrativos e de bom nível. Cada vez mais, a tendência é professores e alunos disporem de seus próprios equipamentos com acesso à internet - notebooks, tabletes, celulares, smartphones - tornando prática, rápida e cômoda a sua utilização. Não há como negar ser a internet um veículo de comunicação e informação que cresce constantemente.

Segundo Pastore (2005), as inovações tecnológicas no mundo do trabalho vêm proporcionando grandes mudanças. Cronologicamente, uma inovação na década de 70 durava cerca de dois anos para que fossem pensados outros meios de seu aprimoramento. Hoje, esse processo é tão veloz que, dependendo da inovação tecnológica, dura menos de duas semanas ou até mesmo dias.

Dentre as diversas concepções sobre as tecnologias, está a que as entende como "um instrumento facilitador na otimização e dinamização do tempo de aula e na concepção de metodologias ativas que requeiram a participação dos alunos de uma forma mais efetiva" (COELHO; HAGUENAUER, 2004, p.2). Mas, a efetivação dos benefícios, seu grau de qualidade, a importância e o significado de seus efeitos condicionam-se e/ou associam-se a um conjunto de circunstâncias e fatores que se relacionam ao perfil profissional dos docentes, às diretrizes políticas educacionais, que regulam o sistema escolar e suas ligações com a sociedade e a cultura digital. Superar descompassos e rupturas entre modos estáveis e institucionalizados de organização da escola, entendê-la no contexto da globalização e da extrema mobilidade promovida pelas TD - não é simples, fácil. Tampouco se dá de modo satisfatório e na medida desejada.

Embora as pesquisas sobre o uso das TD no ensino superior nem sempre destaquem as diferenças entre as modalidades, ele é mais intenso na $\mathrm{EaD}$, também conhecida como educação eletrônica e/ou online. Esta pode ser definida como conjunto de ações de ensinoaprendizagem desenvolvidas por meios telemáticos, como a internet, a vídeo conferência e a teleconferência. A educação a distância tem um sentido mais amplo do que a educação online. Um curso por correspondência é a distância e não necessariamente online (SILVA, 2006). Um curso online pode acontecer de modo presencial.

Os professores do ensino a distância e/ou online e eletrônico ficam limitados a uma obrigação de fazer uso das tecnologias na perspectiva de recursos, pois todo o seu trabalho 
depende das tecnologias atuais. Sobre elas e para delas se apropriarem de modo eficaz, têm muito que aprender. O desafio é ultrapassar a "concepção instrumental” (PEIXOTO, 2012), que delas quase sempre têm, tendo em vista a compreensão de suas relações com a conjuntura social, formativa e profissional de seu trabalho, além das substantivas articulações com a sociedade como um todo. Afinal, a sociedade produz as TD, ao mesmo tempo em que por elas é preservada e reproduzida (CASTELLS, 2007; MATTELART, 2006; LAZZARATO; NEGRI, 2001).

Não se trata apenas de uma reconfiguração nos modos de fazer, nos modos de trabalhar. São novos modos de ser e de se comunicar; novos modos de pensar o mundo e de nele agir ou a ele responder. Portanto, é insuficiente discutir usos e apropriações, adotar posições pró ou contra TD e modalidades de ensino por elas alteradas. Cabe compreender reconfigurações do trabalho e de subjetividades, trazidas pelo uso das TD, em suas diversas formas e intensidades.

Sobre a relação tecnologias e subjetividade, Turkle (2011) citada por Fischer, (2012, p. 1045) reconhece que

[...] nossas subjetividades parecem estar adquirindo contornos preocupantes, num tempo em que as tecnologias de informação e comunicação se apresentam para nós como "arquitetas de nossa intimidade", de uma maneira tal que lá, na second life, sempre somos melhores do que efetivamente somos; lá podemos esconder-nos (embora estejamos cada vez mais expostos); lá, escrevemos mais do que falamos (com o outro). Talvez, sugere a autora, a grande questão é que estamos seduzidos pela tecnologia justamente porque ela toca em nossas maiores vulnerabilidades.

Mais que recursos, as tecnologias provocam substantivas alterações. Penetram o tecido social, o alteram e nele se fazem fortes. Não de uma maneira tão natural, quanto possam acreditar alguns. Há uma historicidade quanto à sua constituição, processo, alcance e consequências sociais. Não surgem por acaso e espontaneamente. De maneira clara e intencional, servem a uma lógica do sistema social, político e econômico, em que a modelagem e controle dos indivíduos pela captura das subjetividades, seja pelo mundo do trabalho, seja pela força do trabalho imaterial, tende a se impor, se expandir e se consolidar cada vez mais. Na vida escolar e no trabalho docente, reduzido este a uma relação comunicativa e a um padrão de interatividade mediado por dispositivos tecnológicos, que se completam e/ou se superpõem, os aparatos tecnológicos afetam mais e mais os seres humanos, podendo colocar em risco sua autonomia e condição de sujeito e de profissional, à medida que secundarizam o seu papel e a natureza do trabalho que exercem. O trabalho docente é uma relação social afetada pelo contexto de uma reestruturação geral do mundo, que o condiciona em sua natureza, conteúdos e formatos. 
Cada vez mais se expande, se consolida e se evidencia a natureza imaterial e virtual do trabalho de professores, seja na modalidade presencial, seja a distância.

Todo contato com o aluno no ensino a distância é feito online através de e-mails, chats, fóruns entre outros. Em algumas universidades são oferecidas aulas presenciais nesta modalidade, aulas quinzenais ou mensais. No entanto, e acompanhando algumas tendências em expansão no mundo inteiro e em diversas áreas do conhecimento, caminha-se para a concorrência progressiva e irreversível dos cursos online em relação aos presenciais. Estes tendem a se expandir menos do que aqueles. $\mathrm{O}$ que no final do século $\mathrm{XX}$ era processo inicial e quase exceção, no século XXI passa a ser central. Tem-se uma inversão do sistema tradicional: o que era central passa a ser periférico; e o que era complementar passa a ser substantivo. Nessa direção, a EaD é tida como meio de inclusão, de democratização do acesso e aproximação da realidade do aluno e de atendimento compatível com suas necessidades.

\begin{abstract}
A Educação a distância $(\mathrm{EaD})$, ao utilizar recursos da web para suportar essa formação, permite aos cidadãos ampliar seus espaços de partilha e aprendizagem, ao mesmo tempo em que flexibiliza os momentos de estudo dos mesmos (ORTH et al, 2013, p. 44).
\end{abstract}

Com mais frequência e em extensões de maior cobertura geográfica, a EaD rompe barreiras e se instala como alternativa e ao mesmo tempo como desafio ao trabalho docente em sua organização, conteúdos e processos. Requerem dos docentes constantes processos formativos e desenvolvimento profissional ao longo de suas trajetórias e carreira. Deles, espera-se permanente atualização das informações e dos conhecimentos gerais; estudo do que é novo para se habilitar a contribuir com o aluno e com a educação, trazendo para os diferentes ambientes educacionais materiais pedagógicos interessantes e mais bem elaborados. O professor de ensino a distância, segundo Lapa e Pretto (2010, p.81-82),

[...] arrisca olhar o novo, em uma educação mediada e dependente do uso de Tecnologias da Informação e Comunicação (TIC), mas tem como referência e prática a realidade do ensino presencial, em que ele está relativamente à vontade, pois ali tem parâmetros e história.

Não há como negar que a formação de educadores " [...] precisa levar em consideração o uso das TIC como elemento auxiliar na socialização do saber pedagógico, a fim de incorporar esses elementos na prática docente" (GONÇALVES; NUNES, 2006, p.4).

Não se deve atribuir toda qualidade do ensino exclusivamente às tecnologias. Há que se cuidar do lugar do professor e da concepção que se tem do seu trabalho no processo educativo, atentando para o como se darão sua presença e intervenção em relação ao conteúdo 
a ser trabalhado, de modo a evitar a armadilha de sua marginalização e/ou substituição pelas tecnologias. Os "recursos tecnológicos por si só não criam aprendizagens significativas" (ENS, 2002, p.38). Isso dependerá de como se conjugam proposta curricular, fatores profissionais e pessoais do professor, organização e condições de seu trabalho, políticas institucionais da escola e outros fatores históricos, sociais e culturais que envolvem a vida escolar. Esses aspectos têm o foco nos docentes dos cursos a distância, mas não se restringem a eles, pois os professores que atuam na modalidade presencial também utilizam as TD nas suas atividades cotidianas. Um exemplo são as páginas e os portais online das universidades que têm um software que possibilita ao professor mandar mensagens aos alunos, enviar materiais das aulas e até mesmo criar fóruns de debate e comunicação entre aluno/professores e alunos/alunos. Assim, eles não têm como ficarem alheios ao mundo tecnológico e dele desconectados.

Dos equívocos às simplificações na relação indivíduo/tecnologias, podem resultar alguns problemas. Dentre eles, conforme Fidalgo, Oliveira et al. (2009), está a confusão entre vida privada e vida profissional, com dificuldade em estabelecer limites de horários de trabalho, lazer e convívio familiar. Para Oliveira (2010), a jornada de trabalho dos professores não aumentou. Ela se tornou mais complexa e mudou a qualidade de trabalho do docente. Arruda (2004) reconhece que o trabalho docente aumentou com as tecnologias e, com ele, principalmente a carga horaria não remunerada que inclui atividades que resultam em trabalho imaterial. A produção desses serviços não resulta em bem material e durável. Define-se o trabalho envolvido nessa produção como trabalho imaterial - ou seja, trabalho que produz um bem imaterial, como serviço, produto cultural, conhecimento ou comunicação (HARDT; NEGRI, 2001, p. 311). Estes são meios de produções da docência. São o "fruto" do trabalho de professores. Para não restringir a imaterialidade do conhecimento, ficando apenas na comunicação, há criação e publicação de materiais que têm materialidade, são concretos e estão disponíveis aos que se interessam pelo que foi criado.

Os professores têm produção conceitual que substitui ou completa a produção de objetos:

\begin{abstract}
A economia do conhecimento está baseada na produção e distribuição do conhecimento e da informação. Assim, na economia do conhecimento os trabalhadores não são operários, nos termos de Sawyer (2008), mas "analistas simbólicos" que manipulam símbolos no lugar de máquinas e que criam artefatos conceituais no lugar de objetos físicos. No trabalho deste analista simbólico, a criatividade e a capacidade de inovação formam parte das competências necessárias para seu desenvolvimento profissional (MARCELO, 2013, p.26). ${ }^{2}$
\end{abstract}

\footnotetext{
${ }^{2}$ Tradução livre do original: "La economia del conocimiento está basada em la producción y distribución del conocimiento y la información. Así, em la economia del conocimiento los trabajadores no son ya operários sino, em términos de Sawyer (2008), "analistas simbólicos" que manipulan símbolos em lugar de máquinas y que crean artefactos conceptuales em lugar de objetos físicos".
} 
Devido ao grande número e fontes de materiais disponíveis, alteram-se as exigências e as demandas do trabalho do professor. Ao mesmo tempo em que lhe são possibilitadas formas diversas de acesso a informações atualizadas, cabe-lhe saber selecioná-las e delas se apropriar satisfatoriamente, tentando exercer controle sobre seus conteúdos e relações com a produção de si.

Qualidade e quantidade do trabalho são reorganizadas em torno de sua imaterialidade. [...] O trabalho imaterial não se reproduz (e não reproduz a sociedade) na forma de exploração, mas na forma de reprodução da subjetividade (LAZZARATO; NEGRI, 2001, p.25 e 30).

Nem sempre especificidades do ambiente de muitas tecnologias de acesso à informação são compreendidas no modo como atingem a docência e a reconfiguram, não só como uma prática pedagógica, mas como exercício de um trabalho e de uma profissão. Isso é cada vez mais evidente, em sua implantação e nos estudos sobre sua entrada, aceitação ou resistência no ensino.

Passada a fase inicial e consolidada a sua incorporação na escola, há um imenso campo de materiais publicados na área e uma indicação de que essa força de trabalho é mais exigida em seu potencial de produção. As tecnologias intensificam e alargam as atividades para além do local de trabalho, ocupando outros ambientes, rompendo as antigas separações entre trabalho e não trabalho e reconfigurando a subjetividade de professores.

\subsection{Do trabalho à subjetividade e saúde de docentes}

Se no início da década de 90 havia dúvidas sobre os rumos e forças das TD no mundo do trabalho, no início do século XXI elas vieram para ficar. Estão redirecionando rumos de vida e de trabalho. Em função delas e por meio delas, firma-se a cultura digital. Sua influência no mundo do trabalho é cada vez maior e chega a tomar conta de várias profissões e de diversos setores.

Na docência superior não é diferente. Reconhece-se o quanto as TD estão presentes no cotidiano docente, após análise das entrevistas realizadas com nove de um total de 820 professores de uma universidade privada da região do Triângulo Mineiro, com larga e consolidada tradição local e regional, que oferece cursos em diversas áreas do conhecimento, e o seu cruzamento com a literatura pesquisada.

A maior parte dos docentes entrevistados trabalha tanto no ensino presencial quanto na EaD. Eles dividem-se nas duas modalidades de ensino. Nelas intercalam atividades nos turnos da manhã, tarde ou noite. Seus principais instrumentos de trabalho - computadores, internet, 
e-mail - viabilizam e consolidam o Ambiente Virtual de Aprendizagem (AVA) na instituição. Eles possibilitam que professor e aluno se comuniquem e dúvidas sobre os conteúdos das disciplinas sejam resolvidas.

No geral, os docentes da EaD não apresentaram nenhuma queixa ou dificuldade em lidar com os chamados recursos tecnológicos. Apenas três disseram que usar as tecnologias pode ser um pouco mais trabalhoso, complexo e cansativo do que ministrar aulas presenciais, pois devem estar conectados a todo o momento em frente à máquina.

Nos cursos presenciais, há professores que também utilizam sem dificuldade as tecnologias. Pode-se atribuir a ausência de dificuldades a um processo de aprendizagem. Afinal, já é relativamente grande o período entre sua entrada na escola e o trabalho docente que nela acontece.

Os dispositivos tecnológicos móveis foram considerados pela maioria dos participantes da pesquisa como recursos que facilitam o processo de ensino-aprendizagem. Como avalia a professora Carla, eles "[...]facilitam alguns trabalhos que você vai desenvolver dentro da sala de aula". Muitos docentes, demonstrando certa tranquilidade e evolução em relação a eles, permitem que os alunos façam uso dos notebooks, celulares, ipads e outros aparelhos dentro de sala de aula, entendendo que podem contribuir no processo ensinoaprendizagem.

Para melhorar ainda mais as condições de interação na sala de aula e "facilitar" a aprendizagem, há professores que adquiriram seus próprios recursos tecnológicos, vendo-os como importantes equipamentos de trabalho. Os mais citados pelos docentes foram os "datasshow", os "computadores", incluindo o programa "power point" e os "vídeos educativos".

Sugerindo profissionalismo e formação para o trabalho, alguns reconheceram ser fundamental ter certo domínio do material, para não correr o risco de se perderem durante a aula e/ou se tornarem dependentes destas tecnologias. Entendem também que a qualidade do ensino não está limitada somente aos recursos.

Embora exista liberdade de alunos e docentes trazerem seus dispositivos móveis, há professores que ainda recorrem às formas tradicionais de ensino, conforme entende Amélia:

(...) como a gente trabalha na área de gestão com pessoas, então a gente trabalha muito com dinâmica de grupo, eu sempre procuro trazer profissionais de outras empresas que tem uma vivência, para compartilhar experiências com os alunos, na parte teórica, mas a gente não pode pensar só na questão da tecnologia. Ela é um recurso para nos ajudar, e não que a gente tenha que ficar dependente dela. 
Houve quem demonstrasse certa resistência em lidar com as tecnologias dentro de sala de aula e até mesmo fora dela. Mesmo admitindo sua importância, não as usa, nem para elaborar um trabalho ou provas, devido à falta de tempo.

Sobre o modo como lidam com as tecnologias em sala de aula, os docentes foram quase unânimes. Relataram que os alunos têm liberdade para trazer seus equipamentos, mas usufruem desta condição apenas se o seu uso relaciona-se ao discutido nas aulas.

Quando eu vejo assim que eles estão utilizando para a matéria, para buscar algum conteúdo, para tirar alguma dúvida eu deixo normal. Agora se eu vejo que ele está no msn, Orkut, no facebook eu peço para desligar, porque isso não é aula (Prof ${ }^{a}$ Roseli).

A falta de compromisso por parte dos alunos foi uma queixa dos docentes. Segundo eles, muitos levam seus equipamentos de casa e não os usam para estudo. Dispersam-se em outros assuntos, tirando a atenção dos demais no ambiente escolar.

Quanto ao perfil dos alunos da $\mathrm{EaD}$, professores admitiram significativas diferenças em relação ao dos cursos presenciais. $\mathrm{Na} \mathrm{EaD} \mathrm{os} \mathrm{discentes} \mathrm{demonstram} \mathrm{um} \mathrm{conhecimento}$ mais heterogêneo, em sua maioria são adultos, tidos como mais experientes, com maturidade e motivações que os levam a fazer o curso com seriedade. Nos presenciais, alguns alunos chegam ao meio acadêmico ainda muito novos, imaturos para seguir aquele caminho, cheios de dúvidas e expectativas que podem ou não serem alcançadas. Utilizam as salas de aulas nem sempre para aproveitamento do conteúdo e despertam a atenção dos que estão a sua volta. Em decorrência disso, as tecnologias foram apontadas, em algumas situações, como concorrentes dos professores. É o que reconhece a professora questionada sobre como os alunos lidam com as tecnologias na sala de aula:

É uma concorrência com o professor. Eu acho que a tecnologia ela ajuda, mas em alguns momentos ela pode também atrapalhar. (...) o computador, é complicado a gente falar, há alunos que preferem ficar com o computador a ouvir ali o professor na sala de aula (Prof ${ }^{\mathrm{a}}$ Amélia).

Os celulares são os grandes vilões nas salas de aula. Os computadores portáteis vêm em segundo lugar. Os docentes entendem que os últimos ainda agregam mais conhecimento ao aluno do que aqueles. Dois, dos nove entrevistados, discordam dos colegas, referindo-se ao uso inadequado dos dispositivos móveis pelos alunos na sala de aula. É o que se deduz da avaliação da professora Laura: 
(...) olha eu não vejo assim como concorrentes, igual outros colegas veem. Não. Na minha aula pode ligar o computador, porque querendo ou não a tecnologia está à disposição do aluno. Então a instituição tem wi-fi. Eu deixo a vontade, eu falo: - olha vocês podem ligar, desde que não me atrapalhem, celulares no silencioso, se tocar não tem problema, sai da sala e atende, desde que não atrapalhe a minha explicação e a do colega.

$\mathrm{Na}$ universidade, lócus da pesquisa, há um sistema de internet livre e gratuito para alunos e profissionais. Para o acesso, basta cadastrar a máquina com o número da matrícula. Mas, funcionalidades e praticidades como estas podem dificultar o trabalho dos professores. Os docentes ficam sem controle daquilo que acontece em sala e correm o risco de terem que enfrentar a dispersão e/ou desinteresse durante as aulas. Especialmente em alguns cursos, são bastante comuns salas de universidades apresentarem 30, 40 alunos por semestre, em cursos não muito disputados. Em cursos com mais alunos, os problemas de perda de controle da sala de aula podem apresentar efeitos de maior extensão para o trabalho do professor e a aprendizagem dos alunos.

Com muitas atribuições a cumprir, o tempo do docente torna-se cada vez mais curto. $\mathrm{O}$ uso de tecnologias favorece a intensificação de suas atividades diárias e o aumento de sua jornada de trabalho, além do contrato estabelecido devido ao acesso a e-mails, buscas de material, pesquisas e uso do ambiente virtual de aprendizagem, de onde eles estiverem. " $\mathrm{O}$ trabalho já não fica circunscrito a um local e nem a um tempo específico, demarcável e definido. Os locais de não-trabalho bem como os tempos de lazer são submetidos assim também à dominação do trabalho" (PUCCI; CERASOLI, 2010, p. 180).

Há professores dependentes e ao mesmo tempo vítimas desses recursos. Alguns nem conseguem diferenciar vida profissional da pessoal. A mistura do trabalho à vida pessoal pode gerar agravos para a saúde psíquica e física dos professores, tais como depressão, exaustão, dores acentuadas de coluna, transtorno alimentar e estresse. São frequentes as queixas de sobrecarga. O docente sente-se preso ao trabalho, sem conseguir fazer outra coisa, por ter que cumprir agenda de compromissos, conforme registra o Prof. Lucio: “(...) esse espaço cultural que dá qualidade de vida, que dá felicidade para o ser humano, eu não tenho aproveitado, pela quantidade de trabalho".

A necessidade de controlar alunos que desvirtuam o foco da aula, sem dúvida, aparece como mais uma sobrecarga para o trabalho docente, com implicações diretas ou indiretas para sua satisfação e saúde. Quando os docentes conseguem bons resultados dentro das salas de aula e em suas tarefas, sentem-se realizados e o trabalho passa a trazer satisfação pessoal e profissional.

Embora parte dos sujeitos entrevistados confesse que a docência ocupa mais tempo de trabalho do que gostariam e, até às vezes, de forma excessiva, chegando a 90\% do tempo de vida pessoal e profissional de um professor, existe quem tenha consciência e reconhecimento 
da necessidade do tempo para cuidar da própria saúde e ter momentos de lazer, como uma docente relata:

(...) minha médica está brigando comigo (risos). Eu estou fazendo uma dieta e ela quer que eu perca quinze quilos, e sem atividade física está muito difícil, ela está exigindo, mas infelizmente com essa carga horária que eu tenho, não posso pensar em nada, mas bem que eu gostaria (Prof ${ }^{a}$ Roseli).

Com uma vida não muito saudável e menor qualidade de vida, os docentes reconhecem a necessidade de criar alguns hábitos, para reverter essa situação e tornar também o trabalho em algo que traga bem-estar. Sobre isso, há o entendimento da necessária redução da carga horária e a importância em saber conciliar vida profissional e pessoal. Porém, ao menos para alguns, a realidade está mudando. É o que reconhece a Prof a Amélia: “(...) tenho priorizado separar a vida pessoal da profissional. Antes não fazia isso e a qualidade de vida foi a zero... O planejamento ajuda. Quando se trabalha organizado, tem-se menos trabalho".

As TD, enquanto favorecem maior mobilização do sujeito no trabalho, associadas ao aumento das atribuições e exigências apresentadas aos professores, são responsáveis por grande parte dos seus problemas e queixas. A qualidade de vida cai e com isso podem aparecer incômodos, desconfortos, desmotivação, baixa realização profissional e autoestima reduzida, devido à insatisfatória remuneração e a falta de reconhecimento profissional.

Além da formação e da abertura ao permanente desenvolvimento profissional, a docência demanda muita dedicação por parte do professor, equilíbrio na relação tempo e quantidade de tarefas, planejamento e controle de prioridades, tendo em vista o compromisso social e o atendimento aos novos desafios da profissão no contexto da era digital.

\section{Considerações finais}

As tecnologias têm uma grande influência na vida dos professores. A cada dia eles são expostos a novas exigências e desafios que requerem abertura a novas conquistas, descobertas e aprendizagens. As atividades a realizar são em maior número e demandam sempre mais dedicação, empenho e tempo de trabalho, tornando comuns as queixas sobre as longas jornadas de trabalho, que se estendem e se intensificam com o uso das tecnologias. Daí podem surgir efeitos negativos para a saúde dos docentes, que expostos a condições de muito trabalho, acúmulo de tarefas e de atribuições funcionais, ficam propensos a desenvolver doenças,redução da qualidade de vida, além de insatisfação com as condições e produtos do seu trabalho.

O aluno, hoje, tem mais informações, porém menos conhecimento. Ao mesmo tempo em que lhes são disponíveis recursos tecnológicos, pouco uso deles fazem para fins 
educativos. Eles entram em concorrência com os docentes. Lidar com as TD na sala de aula pode ser um problema para o professor, se ele as tem como suas concorrentes. No entanto, há os que não as consideram assim, e aliam-se a elas, tendo em vista bons resultados no processo ensino-aprendizagem.

Considerada a atuação, segundo as modalidades, os professores da EaD são os que mais convivem com as TD. Seu uso excessivo e prolongado pode concorrer para o aumento das jornadas de trabalho e tornar as atividades dos docentes bastante cansativas, mantendo-os sob controle e submetendo-os a um ritmo intensificado de produção. Assim, ao invés de gestores de si, podem se tornar reféns dos recursos tecnológicos, enquanto são eles quase sempre as únicas ferramentas de ligação entre aluno e professor.

Maiores estudos na área da docência são importantes. Principalmente os ligados ao mundo virtual e suas relações com a saúde e a qualidade de vida de professores, em virtude da explícita e disseminada intensificação do ritmo de trabalho docente; demandando atenção e cuidados com as condições do trabalho, de forma a preservar-lhe a natureza de sua dimensão educativa e transformadora do ser humano.

\section{Referências}

ARRUDA, E. Ciberprofessor - Novas Tecnologias, Ensino e Trabalho Docente. Belo Horizonte: Autêntica/FCHFUMEC, 2004. 136.p

CASTELLS, M. A sociedade em rede. São Paulo: Paz e terra, 1999. 698 p.

COELHO, C. U. F.; HAGUENAUER, C. J. As Tecnologias da Informação e da Comunicação e sua Influência na Mudança do Perfil e da Postura do Professor. Colabor@, Revista Digital da CVA, v. 2, n. 6, 2004.

ENS, R. T. Relação professor, aluno, tecnologia: um espaço para o saber, o saber fazer, o saber conviver e o saber ser. Colabor@, Revista Digital da CVA, Curitiba, v. 1, n. 3, p. 3745, 2002.

FIDALGO, F.; OLIVEIRA, M. A. M.; FIDALGO, N. L. R. (orgs.). A intensificação do trabalho docente: Tecnologias e produtividade. Campinas, SP: Papirus, 2009. 240 p.

FISCHER, R. M. B. "Mitologias" em torno da novidade tecnológica em educação. Educ. Soc., Campinas, v.33, n. 121, p. 1037-1052, out./dez. 2012. Disponível em: <http://cedes.unicamp.br>. Acesso 03 nov. 2013.

GONÇALVES, M. T. L.; NUNES, J. B. C. Tecnologias de informação e comunicação: limites na formação e prática dos professores. In: 29ª Reunião Anual da ANPEd, 2006, 
Caxambu. Educação, cultura e conhecimento na contemporaneidade: Desafios e Compromissos, 2006. p. 1-18

LAPA, A; PRETTO, N. D. L. Educação a distância e precarização do trabalho docente. Em Aberto, Brasília, v. 23, n. 84, p. 79-97, Nov. 2010. Disponível em: < em aberto.inep.gov.br/index.php/em aberto/article/view/1792/1355>. Acesso em 26 set. 2013.

LAZZARATO, M; NEGRI, A. Trabalho imaterial: formas de vida e produção de subjetividade. Rio de Janeiro: DP\&A, 2001. 311 p.

MARCELO, C. Las tecnologías para la innovación y la práctica docente. Revista Brasileira de Educação, v.18, n.52, jan./mar. 2013. Disponível em http:<//scielo.br> Acesso em:10 set. 2013.

MINAYO, M. C. de S. O desafio do conhecimento: pesquisa qualitativa em saúde. $11^{\text {a }}$ ed. São Paulo: Hucitec, 2014.

MATTERLART, A. História da sociedade da informação. 2ed. São Paulo: Loyola, 2006.

OLIVEIRA, W. L. d. As tecnologias da informação e comunicação e a intensificação do trabalho docente. Revista: Educação, Formação \& Tecnologias, v. 3 n.1, p. 84-95, 2010. Disponível em: <http://eft.educom.pt/index.php/eft/article/download/89/94>. Acesso em 26 set. 2013.

ORTH, M. A; et al. Ambientes virtuais de aprendizagem e formação continuada de professores na modalidade a distância. Conjectura: Filos. Educ., Caxias do Sul, v. 18, n. 1, p. 42-58, 2013. Disponível em: <

http://www.ucs.br/etc/revistas/index.php/conjectura/article/viewFile/2037/1200>. Acesso em 20 nov. 2013

PASTORE, J. A Evolução Tecnológica e suas Repercussões nas Relações do Trabalho. São Paulo: Instituto Brasileiro de Ciência Bancária e Revista Direito do trabalho.

Julho/Setembro de 2005. Disponível em:

<http://www.josepastore.com.br/artigos/rt/rt_246.htm>. Acesso em 02 dez. 2013

PEIXOTO, J; ARAÚJO, C. H. dos S. Tecnologia e educação: algumas considerações sobre o discurso pedagógico contemporâneo. Revista Educação e Sociedade.

Campinas v.33 n.118 p. 253-268. jan./mar. 2012. Disponível em:

<http://www.scielo.br/pdf/es/v33n118/v33n118a16.pdf>. Acesso em 17 dez. 2013.

PUCCI, B.; CERASOLI, J. F. As novas tecnologias e a intensificação do trabalho docente na universidade. Revista Educação e filosofia, Uberlândia, v. 24, n. 47, p. 171-190, jan./jun. 2010. Disponível em: 
<http://www.seer.ufu.br/index.php/EducacaoFilosofia/article/view/7420>. Acesso em 22 set. 2013.

RIFKIN, Jeremy. A era do acesso. São Paulo: MakronBooks, 2001. 272 p.

SILVA, Marcos (org). Educação online. 2. ed. São Paulo: Edições Loyola, 2006. 512 p.

Recebido em: 14/02/2014

Revisado em: 20/07/2015

Aprovado para publicação em: 24/11/2015

Publicado em: 31/08/2016 